\title{
Planning and Designing the Improving Addiction Care Team (IMPACT) for Hospitalized Adults with Substance Use Disorder
}

\author{
Honora Englander, MD ${ }^{1,2 *}$, Melissa Weimer, DO, MCR ${ }^{1,3}$, Rachel Solotaroff, MD, MCR ${ }^{2}$, Christina Nicolaidis, MD, MPH',4, \\ Benjamin Chan, $\mathrm{MS}^{1}$, Christine Velez, MSW${ }^{4}$, Alison Noice, MA, CADC-III ${ }^{3}$, Tim Hartnett, MSW, MHA ${ }^{3}$, Ed Blackburn, MA², \\ Pen Barnes, MBBS, PhD ${ }^{1}$, P. Todd Korthuis, MD, MPH ${ }^{1}$
}

\begin{abstract}
${ }^{1}$ Oregon Health \& Science University, Portland, Oregon; ${ }^{2}$ Central City Concern, Portland, Oregon; ${ }^{3}$ CODA, Inc., Portland, Oregon; ${ }^{4}$ School of Social Work, Portland State University, Portland, Oregon.
\end{abstract}

People with substance use disorders (SUD) have high rates of hospitalization and readmission, long lengths of stay, and skyrocketing healthcare costs. Yet, models for improving care are extremely limited. We performed a needs assessment and then convened academic and community partners, including a hospital, community SUD organizations, and Medicaid accountable care organizations, to design a care model for medically complex hospitalized patients with SUD. Needs assessment showed that $58 \%$ to $67 \%$ of participants who reported active substance use said they were interested in cutting back or quitting. Many reported interest in medication for addiction treatment (MAT). Participants had high rates of costly readmissions and longer than expected length of stay. Community stakeholders identified long wait times and lack of resources for medically complex patients as key barriers. We developed the Improving Addiction Care Team (IMPACT), which includes an inpatient addiction medicine consultation service, rapid-access pathways to posthospital SUD treatment, and a medically enhanced residential care model that integrates antibiotic infusion and residential addiction care. We developed a business case and secured funding from Medicaid and hospital payers. IMPACT provides one pathway for hospitals, payers, and communities to collaboratively address the SUD epidemic. Journal of Hospital Medicine 2017;12:339-342. (C) 2017 Society of Hospital Medicine
Addiction is a national epidemic that represents both a pressing need and a significant burden to the healthcare system. ${ }^{1}$ Hospitals are increasingly filled with people admitted for medical complications of substance use disorders (SUD). ${ }^{2}$ People with SUD have longer lengths of stay (LOS) and high readmission rates. ${ }^{3}$ Hospitalization often does not address the root cause-the SUD. For example, many hospitals replace heart valves and deliver prolonged courses of intravenous (IV) antibiotics for endocarditis from injection drug use but do not offer addiction medicine consultation, medication for addiction treatment (MAT), or linkage to posthospital SUD treatment. ${ }^{4,5}$

Hospitalization can provide reachable moments for initiating addiction care. ${ }^{6}$ Medications for opioid ${ }^{7}$ and alcohol use disorders $^{8}$ can be started during hospitalization, promoting engagement in outpatient SUD care $^{7}$ and increased uptake of MAT, ${ }^{7-9}$ and reducing readmissions. ${ }^{8,10}$ Yet, medications for SUD are underprescribed, ${ }^{11,12}$ and most hospitals lack inpatient addiction medicine services and pathways to timely SUD care after discharge. Furthermore, traditional SUD treatment programs are often not equipped to manage medically complex patients or they have long waitlists. ${ }^{13}$ Most behavioral-physical health integration occurs in ambulatory settings. This fails to engage patients who

\footnotetext{
*Address for correspondence and reprint requests: Honora Englander, MD, Mail Code BTE 119, Oregon Health \& Science University, 3181 SW Sam Jackson Park Rd, Portland, OR 97239; Telephone: 971-404-5725; Fax: 503-4941159; E-mail: englandh@ohsu.edu
}

Received: September 25, 2016; Revised: February 8, 2017; Accepted: February 16, 2017

2017 Society of Hospital Medicine DOI 10.12788/jhm.2736 do not access primary care. There is an urgent need for models that can improve care for hospitalized patients with SUD.

Here, we describe our experience using patient needs assessment to engage stakeholders and drive local systems change. We also describe the resulting care model, the Improving Addiction Care Team (IMPACT). Our experience provides a potentially useful example to other hospitals and communities seeking to address the national SUD epidemic.

\section{METHODS}

\section{Setting}

In 2012, Oregon transformed its Medicaid system by establishing 16 regional "coordinated care organizations" (CCOs) to improve outcomes and slow healthcare spending. ${ }^{14}$ In a $\mathrm{CCO}$ environment, hospitals assume increased financial risk, yet reforms have focused on the outpatient setting. Therefore, executive leadership at Oregon Health \& Science University (OHSU), an urban academic medical center, asked clinician-leaders to design point-of-care improvements for Medicaid-funded adults and build on existing models to improve care for socioeconomically vulnerable adults. ${ }^{15,16}$ One priority that emerged was to make improvements for hospitalized adults with SUD. Of the adult inpatients at OHSU, 30\% have Medicaid and 15\% have SUD by administrative data alone. Before we started our work, OHSU lacked inpatient addiction medicine services.

\section{Local Needs Assessment}

To understand local needs and opportunities, we surveyed hospitalized adults with SUD. We used the electronic health 
record to generate a list of inpatients flagged by nurses for risky alcohol or drug use. A research assistant screened consecutive adults ( $\geq 18$ years old) and invited those who screened positive for alcohol use (Alcohol Use Disorders Identification Test-Consumption [AUDIT-C]) $)^{17}$ or drug use (single-item screener $)^{18}$ to participate. We excluded non-English speakers, incarcerated adults, people using only marijuana or tobacco, psychiatry inpatients, and people unable to consent. Surveys assessed social and demographic factors, healthcare utilization, substance use severity, and treatment experience. Participants who reported high-risk illicit drug or alcohol use ${ }^{19}$ were asked to indicate their readiness to change on a 3-point scale developed for this study. Response range included: no interest, interest in cutting back, or interest in quitting. A subset of participants completed in-depth qualitative interviews exploring patient perceptions of substance use treatment needs. ${ }^{20}$ We obtained hospital administrative data from hospital financial services.

\section{Partner Engagement}

We identified community partners with which we had an individual or organizational relationship and a common interest and potential for collaboration. All invited partners agreed to attend initial meetings. We convened leadership and frontline staff across partners. OHSU staff included hospital nursing and social work leaders; infectious disease, hospitalist, and addiction physicians; and health services researchers. Community organizations included Central City Concern (CCC), a community organization serving people facing homelessness and addiction; CODA, Inc., a nonprofit SUD treatment agency; and Coram/CVS infusion pharmacy.

Collectively, we reviewed needs assessment findings and examples from the literature ${ }^{7-9}$ to develop strategies to address patient and system needs. We used patient narratives to foster alignment and prioritized areas in which integration could improve quality and costs. We assumed we would petition OHSU and/or Medicaid CCOs to finance efforts and saved potentially challenging budget discussions for later, when partnerships would be more developed. Our task force attended more than 3 large-group meetings and numerous small-group meetings to develop IMPACT.

\section{RESULTS}

\section{Needs Assessment}

Between September 2014 and April 2015, a research assistant approached 326 patients. Of these, 235 (72\%) met study inclusion criteria, and 185 (78\%) agreed to participate (Table 1). Of people who reported any substance use within the preceding 3 months, $58 \%$ of alcohol users and $67 \%$ of drug users said they were interested in cutting back or quitting. Fifty-four percent of participants with moderate- to high-risk opioid use and $16 \%$ with moderate- to high-risk alcohol use reported strong interest in MAT. In qualitative interviews, participants described inadequately treated withdrawal, the importance of trust and choice, and long wait times as a barriers to entering treatment after hospital discharge. ${ }^{20}$

Administrative data revealed high rates of hospital re-
TABLE 1. Needs Assessment Participant Characteristics

\begin{tabular}{lc}
\hline Substance Use & $\mathrm{n}(\%)$ \\
\hline Total participants & 185 \\
\hline Any alcohol use in the past 3 months & $109 / 185(59)$ \\
\hline Any opioid use in the past 3 months & $68 / 185(37)$ \\
\hline Any druga use in the past 3 months & $137 / 185(74)$ \\
\hline Interest in cutting back or quitting & \\
Alcohol & $63 / 109(58)$ \\
Drugs & $92 / 137(67)$ \\
\hline Moderate - high risk substance use & \\
Alcohol & $82 / 185(44)$ \\
Amphetamines & $74 / 185(40)$ \\
Opioids & $72 / 185(39)$ \\
Cocaine & $23 / 185(12)$ \\
\hline Past 3 month polysubstance use & $113 / 185(61)$ \\
\hline Interest in MAT for alcohol use disorder among moderate-high risk users & $13 / 82(16)$ \\
\hline Interest in MAT for opioid use disorder among moderate-high risk users & \\
Any MAT & $39 / 72(54)$ \\
Methadone & $26 / 72(36)$ \\
Buprenorphine & $23 / 72(32)$ \\
\hline
\end{tabular}

${ }^{a}$ Cocaine, amphetamines, inhalants, sedatives, hallucinogens, opioids.

NOTE: Abbreviation: MAT, medications for addiction treatment.

admissions and longer than expected LOS (Figure). Mean LOS was 10.26 days - 4 days more than medicine patients'. Mean LOS was high among participants who required longterm IV antibiotics, particularly those with endocarditis or osteomyelitis (21.75 days; range, 1.00-51.00 days). We excluded one outlier with a 116-day hospitalization.

\section{Intervention Design}

Mapping needs to intervention components. We mapped needs assessment findings to 3 main IMPACT components: inpatient addiction medicine consultation service, pathways to posthospital SUD treatment, and medically enhanced residential treatment (MERT) (Table 2).

Inpatient addiction medicine consultation service. We developed this service to address patients' report of high readiness to change and interest in starting MAT in the hospital. Community partners highlighted the need for peers to increase engagement and trust. Therefore, we included a physician, a social worker, and two peers on our team. The inpatient service engages patients, advises on withdrawal and pain, performs SUD assessments, initiates MAT, and provides counseling and treatment.

Pathways to posthospital SUD treatment. As pathways from hospital to community SUD treatment were lacking, and long administrative wait times limited access to community treatment, we employed "in-reach" liaisons-community SUD treatment staff who perform in-hospital assessments to triage and coordinate care across systems. Given that patients 


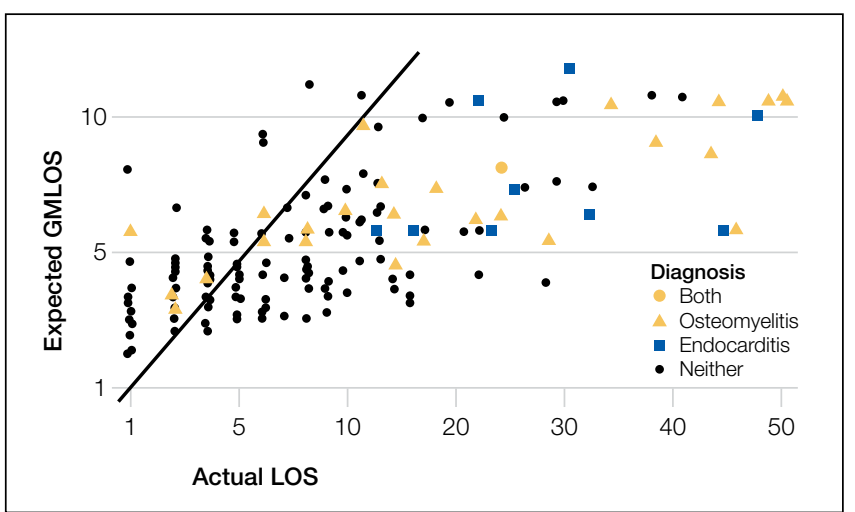

FIG. Hospital LOS among needs assessment patients.

NOTE: Abbreviations: GMLOS, geometric length of stay; LOS, length of stay.

value having treatment choices, we linked pathways to an array of MAT and abstinence-based treatments, including office-based, intensive outpatient and residential levels of care. For patients who live outside the Portland area, we developed relationships with rural stakeholders and engaged the help of the Oregon State Opioid Authority in introducing our program to SUD treatment providers around the state.

Medically Enhanced Residential Treatment (MERT). In many cases where patients required prolonged courses of IV antibiotics, hospital stays were longer for two reasons: Athome central-line self-administration of antibiotics was deemed unsafe, and patients were denied admission to a skilled nursing facility due to history of substance use. These long LOS create an opportunity to initiate and engage patients in treatment, and to render savings by shifting care to a residential addiction treatment setting that can accommodate IV antibiotic administration and MAT. We increased residential staffing and collaborated with a home infusion pharmacy to administer daily infusions on site.

\section{Funding the Intervention}

We used administrative data to estimate potential savings and tailored a business case to $\mathrm{CCO}$ and hospital payers. The CCO business case centered on hospitalization as an opportunity to engage out-of-treatment adults and potentially reduce high-cost readmissions by managing physical and behavioral health needs. Working within budgeting time lines, we used data from the first 165 participants. These participants had 137 readmissions over a mean observation period of 4.5 months. Mean charge per readmission was $\$ 31,157$ (range, \$699-\$206,596) and was highest for people with endocarditis (mean, $\$ 55,493$; range, $\$ 23,204-\$ 145,066$ ) and osteomyelitis (mean, \$68,774; range, \$29,359-\$124,481). We estimated that a $10 \%$ reduction in 6 -month readmissions could avoid $\$ 674,863$ in charges.

For the hospital, the primary financial incentive was reduced LOS. Given the possibility of shortening hospitalization through MERT, we estimated a 20\% mean LOS reduction; for budgeting, we estimated a conservative $10 \%$ reduction. A $10 \%$ mean LOS reduction would free 205 bed-days $(10 \% \times 10.26$ days mean LOS $\times 200$ patients) and create space for another 32 inpatient admissions in year 1 , assuming no change from medical patients'

TABLE 2. Key IMPACT Elements, Including Year 1 Enrollment Targets, Staff Descriptions and Roles, and Allocated Resources

\begin{tabular}{|c|c|c|c|}
\hline $\begin{array}{l}\text { Key Findings of } \\
\text { Needs Assessment }\end{array}$ & $\begin{array}{l}\text { Program Element and } \\
\text { Year } 1 \text { Enrollment Target }\end{array}$ & Staff Descriptions and Roles & $\begin{array}{l}\text { Allocated Resource and } \\
\text { Staffing Rationale }\end{array}$ \\
\hline $\begin{array}{l}\text { Hospitalization provides reachable } \\
\text { moments } \\
\text { OHSU lacked expertise to } \\
\text { assess, engage, and initiate SUD } \\
\text { treatment } \\
\text { Engagement and trust are key }\end{array}$ & $\begin{array}{l}\text { Hospital-based addiction } \\
\text { medicine consultation } \\
\text { service } \\
200 \text { patients }\end{array}$ & $\begin{array}{l}\text { Social worker performs ASAM assessment, uses motivational interview- } \\
\text { ing to engage patients, initiates evidence-based SUD treatment, and } \\
\text { coordinates posthospital addiction care } \\
\text { Physician advises on withdrawal and pain management and initiates MAT } \\
\text { Peers support patient engagement in hospital and across transition to } \\
\text { community SUD care }\end{array}$ & $\begin{array}{l}\text { 0.5 FTE physician—half-day weekday coverage } \\
\text { based on projection that half the patients would need } \\
\text { physician consultation and MAT } \\
\text { 1.0 FTE social worker-expected case load of about } \\
6-8 \text { patients/day } \\
\text { 1.4 FTE peer mentors—-peers would be present } 7 \\
\text { days/week, including some evening hours }\end{array}$ \\
\hline $\begin{array}{l}\text { No pathways from hospital to } \\
\text { outpatient addiction treatment } \\
\text { Long community wait times }\end{array}$ & $\begin{array}{l}\text { "In-reach" liaison supports } \\
\text { rapid-access pathways to } \\
\text { community SUD care after } \\
\text { hospital discharge } \\
100 \text { patients }\end{array}$ & $\begin{array}{l}\text { CADCs from partner organizations "reach in" to hospital, describe } \\
\text { community treatment options, support triage and linkage, and serve } \\
\text { as points of contact as patients transition across hospital, jail, skilled } \\
\text { nursing facility, and community SUD treatment }\end{array}$ & 0.5 FTE CADC—at each partner site \\
\hline $\begin{array}{l}\text { Patients who require long courses } \\
\text { of IV antibiotics have very long } \\
\text { hospital stays } \\
\text { Residential SUD treatment } \\
\text { programs not equipped for } \\
\text { medically complex patients }\end{array}$ & $\begin{array}{l}\text { Medically Enhanced } \\
\text { Residential Treatment brings } \\
\text { IV antibiotics and nursing care into } \\
\text { residential addiction setting } \\
30 \text { patients }\end{array}$ & $\begin{array}{l}\text { Home infusion pharmacy administers daily IV antibiotics and performs } \\
\text { weekly central catheter dressing changes } \\
\text { Registered nurse supports care coordination and on-site infusion, basic } \\
\text { wound care, and other nursing needs } \\
\text { Physician prescribes MAT in residential program and provides oversight } \\
\text { for medically complex patients } \\
\text { Residential program coordinator manages bed flow to support timely } \\
\text { access to residential beds } \\
\text { Infectious disease team uses video technology to conduct weekly virtual } \\
\text { bedside rounds }\end{array}$ & $\begin{array}{l}\text { Payment for } 6 \text { days/week home infusion pharmacy } \\
\text { costs (insurance plans cover once-weekly home } \\
\text { infusion) } \\
0.7 \text { FTE registered nurse } \\
0.1 \text { FTE community addiction physician } \\
0.2 \text { FTE residential program coordinator } \\
\text { Hospital infectious disease team supports } 30 \text { minutes/ } \\
\text { week telehealth rounds }\end{array}$ \\
\hline
\end{tabular}

NOTE: Abbreviations: ASAM, American Society of Addiction Medicine; CADC, certified alcohol and drug counselor; FTE, full-time equivalent; IMPACT, Improving Addiction Care Team; IV, intravenous; MAT, medication for addiction treatment; OHSU, Oregon Health \& Science University; SUD, substance use disorder. 
6.26 days mean LOS. The future of bundled payments further bolstered our business case, as did the potential to improve care quality, reduce nonproductive staff time, and increase institutional learning about SUD. Overall program costs approximated projected savings, and the hospital and a local CCO agreed to equally share the costs of the intervention (Table 2).

\section{DISCUSSION}

We have described an innovative approach to developing an SUD intervention for hospitalized adults. Using a process of broad stakeholder engagement, data-driven understanding of population needs, and analysis of financial incentives, we built consensus and secured funding for a multicomponent intervention across hospital and post-acute care settings. Other studies have demonstrated the feasibility and efficacy of starting a single medication for a specific indication ${ }^{7-9}$ (eg, methadone for opioid use disorder), yet strategies for expanding SUD services in hospitals and facilitating posthospital treatment linkages remain scarce. ${ }^{21}$ Our model addresses a widespread need and could be adapted to other hospitals, SUD treatment organizations, and Medicaid payers.

Our experience has several limitations. First, it took place at a single academic medical center in Oregon, a Medicaid expansion state. Second, our needs assessment involved a convenience sample of limited racial/ethnic diversity. Third, almost all patients had insurance, which could limit generalizability. Fourth, to secure funding, it was essential we had a clinical

\section{References}

1. Volkow N, Frieden TR, Hyde PS, Cha SS. Medication-assisted therapies-Tackling the opioid-overdose epidemic. N Engl J Med. 2014; 370:2063-2066.

2. Ronan MV, Herzig SJ. Hospitalizations related to opioid abuse/dependence and associated serious infections increased sharply, 2002-12. Health Aff (Millwood). 2016;35(5):832-837.

3. Walley AY, Paasche-Orlow M, Lee EC, et al. Acute care hospital utilization among medical inpatients discharged with a substance use disorder diagnosis. J Addict Med. 2012;6(1):50-56.

4. Rosenthal ES, Karchmer AW, Thiesen-Toupal J, Castillo RA, Rowley CF. Suboptimal addiction interventions for patients hospitalized with injection drug use-associated infective endocarditis. Am J Med. 2016;129(5):481-485.

5. Fanucchi L, Lofwall MR. Putting parity into practice-integrating opioid-use disorder treatment into the hospital setting. N Engl J Med. 2016;379(9):811-813.

6. Pollini RA, O'Toole TP, Ford D, Bigelow G. Does this patient really want treatment? Factors associated with baseline and evolving readiness for change among hospitalized substance using adults interested in treatment. Addict Behav. 2006;31(10):1904-1918

7. Liebschutz JM, Crooks D, Herman D, et al. Buprenorphine treatment for hospitalized, opioid-dependent patients: a randomized clinical trial. JAMA Intern Med. 2014;174(8):1369-1376.

8. Wei J, Defries T, Lozada M, Young N, Huen W, Tulsky J. An inpatient treatment and discharge planning protocol for alcohol and dependence: efficacy in reducing 30-day readmissions and emergency department visits. J Gen Intern Med. 2015;30(3):365-370.

9. Shanahan CW, Beers D, Alford DP, Brigandi E, Samet JH. A transitional opioid program to engage hospitalized drug users. J Gen Intern Med. 2010;25(8):803-808.

10. Pecoraro A, Horton T, Ewen E, et al. Early data from Project Engage: a program to identify and transition medically hospitalized patients into addictions treatment. Addict Sci Clin Pract. 2012;7:20.

11. National Center on Addiction and Substance Abuse; Addiction Medicine: Closing the Gap between Science and Practice. June 2012. http://www.centeronaddiction.org/addiction-research/reports/addiction-medicine-closing-gap-between-science-and-practice. Accessed May 2, 2016.

12. Center for Behavioral Health Statistics and Quality, Substance Abuse and Mental Health Services Administration, US Department of Health and Human Services. champion who was persuasive with hospital and CCO leadership; though increasing disease burden and skyrocketing costs ${ }^{2}$ may drive administrators' increased demand for ways to address SUD in hospitalized adults.

Our experience has several key implications. First, diverse partners were vital at all stages of program design, suggesting hospitals should look beyond traditional healthcare partners to address the SUD epidemic. Second, an interprofessional team that includes physicians, social workers, and peers may better engage patients and address complex system needs. Finally, a planned IMPACT evaluation will assess effects on substance use, healthcare use, and costs.

The United States faces a burgeoning SUD epidemic. Our experience describes an innovative care model and supports the idea that hospitals may play a leading role in convening partners, providing treatment, and driving population health improvements for adults with SUD.

\section{Acknowledgment}

The authors would like to acknowledge Peter Rapp and Thomas Yackel for leadership support; Tara Williams for administrative data support; Sarann Bielavitz and Naomi Wright for project management support, and Lynn Smith-Stott and Maria Michalczyk for help with model design. This work was presented at the American Society of Addiction Medicine national conference in Baltimore, MD in April 2016.

Disclosure: This work was funded by Oregon Health \& Science University and CareOregon. The authors have no conflicts of interest to disclose.

Results From the 2010 National Survey on Drug Use and Health: Summary of National Findings. Rockville, MD: Center for Behavioral Health Statistics and Quality, Substance Abuse and Mental Health Services Administration, US Dept of Health and Human Services; 2011. NSDUH series H-41, HHS publication SMA 11-4658. https://www.samhsa.gov/data/sites/default/files/NSDUHNationalFindingsResults2010-web/2k10ResultsRev/NSDUHresultsRev2010.pdf. Published September 2011. Accessed March 31, 2017.

13. Vestal C. Few doctors are willing, able to prescribe powerful anti-addiction drugs. http://www.pewtrusts.org/en/research-and-analysis/blogs/stateline/2016/01/15/ few-doctors-are-willing-able-to-prescribe-powerful-anti-addiction-drugs. Published January 15, 2016. Accessed May 2, 2016.

14. McConnell KJ. Oregon's Medicaid coordinated care organizations. JAMA. 2016;315(9):869-870.

15. Englander H, Kansagara D. Planning and designing the Care Transitions Innovation (C-TraIn) for uninsured and Medicaid patients. J Hosp Med. 2012;7(7):524529

16. Englander H, Michaels L, Chan B, Kansagara D. The Care Transitions Innovation (C-TraIn) for socioeconomically disadvantaged adults: results of a cluster randomized controlled trial. J Gen Intern Med. 2014;29(11):1460-1467.

17. Bush K, Kivlahan DR, McDonell MB, Fihn SD, Bradley KA. The AUDIT alcohol consumption questions (AUDIT-C): an effective brief screening test for problem drinking. Ambulatory Care Quality Improvement Project (ACQUIP). Alcohol Use Disorders Identification Test. Arch Intern Med. 1998;158(16):1789-1795.

18. Smith PC, Schmidt SM, Allensworth-Davies D, Saitz R. A single-question screening test for drug use in primary care. Arch Intern Med. 2010;170(13):11551160 .

19. Humeniuk R, Ali R, Babor TF, et al. Validation of the Alcohol, Smoking and Substance Involvement Screening Test (ASSIST). Addiction. 2008;103(6):1039. 1047.

20. Velez CM, Nicolaidis C, Korthuis PT, Englander H. "It's been an experience, a life learning experience": a qualitative study of hospitalized patients with substance use disorders. J Gen Intern Med. 2017;32(3):296-303.

21. Gryczynski J, Schwartz RP, O'Grady KE, Restivo L, Mitchell SG, Jaffe JH. Understanding patterns of high-cost health care use across different substance user groups. Health Aff (Millwood). 2016.;35(1):12-19. 